\title{
ANTIVIRAL ACTIVITY OF THE LIPPIA GRAVEOLENS (MEXICAN OREGANO) ESSENTIAL OIL AND ITS MAIN COMPOUND CARVACROL AGAINST HUMAN AND ANIMAL VIRUSES
}

\author{
Marciele Ribas Pilau ${ }^{1}$, Sydney Hartz Alves ${ }^{1 *}$, Rudi Weiblen ${ }^{2}$, Sandra Arenhart ${ }^{2}$, Ana Paula Cueto ${ }^{1}$, Luciane Teresinha \\ Lovato ${ }^{1}$
}

${ }^{1}$ Departamento de Microbiologia e Parasitologia, Universidade Federal de Santa Maria, Santa Maria, RS, Brasil; ${ }^{2}$ Departamento de Medicina Veterinária Preventiva. Universidade Federal de Santa Maria, Santa Maria, RS, Brasil.

Submitted: December 27, 2010; Returned to authors for corrections: February 15, 2011Approved: May 30, 2011.

\begin{abstract}
Mexican oregano (Lippia graveolens) is a plant found in Mexico and Central America that is traditionally used as a medicinal herb. In the present study, we investigated the antiviral activity of the essential oil of Mexican oregano and its major component, carvacrol, against different human and animal viruses. The MTT test (3-4,5-dimethythiazol-2yl)-2,5-diphenyl tetrazolium bromide) was conducted to determine the selectivity index (SI) of the essential oil, which was equal to 13.1, 7.4, 10.8, 9.7, and 7.2 for acyclovirresistant herpes simplex virus type 1 (ACVR-HHV-1), acyclovir-sensitive HHV-1, human respiratory syncytial virus (HRSV), bovine herpesvirus type 2 (BoHV-2), and bovine viral diarrhoea virus (BVDV), respectively. The human rotavirus (RV) and BoHV-1 and 5 were not inhibited by the essential oil. Carvacrol alone exhibited high antiviral activity against RV with a SI of 33, but it was less efficient than the oil for the other viruses. Thus, Mexican oregano oil and its main component, carvacrol, are able to inhibit different human and animal viruses in vitro. Specifically, the antiviral effects of Mexican oregano oil on ACVRHHV-1 and HRSV and of carvacrol on RV justify more detailed studies.
\end{abstract}

Key words: Verbenaceae, antimicrobial activity, RNA virus, DNA virus, condimental herbs.

\section{INTRODUCTION}

Viruses are the agents of several infectious diseases $(4,5$, $10,11,32)$, meanwhile there are a small number of antiviral drugs available (13). Plant essential oils and extracts have been examined for their possible antiviral activities, including the essential oils of some commonly used culinary herbs (24). Lippia graveolens is a plant in the Verbenaceae family that is commonly known as Mexican oregano. It is widely used in
Mexico as food seasoning and a folk remedy $(23,31)$. Scientific data support the use of Mexican oregano as an antibacterial and the analysis of the chemical constituents of the Lippia graveolens used in these studies has indicated high carvacrol content (23), which may be responsible for the bacterial inhibition in this case. However, while the antibacterial activity of Lippia graveolens and its major compounds has been demonstrated, its potential antiviral effects have not yet been examined. 
The human herpesvirus type 1 (HHV-1) is an enveloped DNA virus in the Herpesviridae family which is widespread in the human population, primarily causing herpes labialis and gingivostomatitis (32). Nucleoside analogues like acyclovir are widely used for HHV-1 treatment. However, the increasing prevalence of drug-resistant HHV-1 strains, mainly isolated from immunocompromised individuals, is a serious concern in the clinic (18). A search in the literature shows that both HHV1 and 2 are probably the most studied viruses concerning antiviral activity of natural products $(24,26)$. HHV-1 was efficiently inhibited in vitro by the essential oils and extracts from a variety of plants $(2,14)$, and also by extracts from other sources as fungi (7) and marine sponges (12).

The human respiratory syncytial virus (HRSV) is one of the main agents of bronchiolitis and pneumonia in children and plays a major role in the aetiology of pneumonia in elderly individuals (21). HRSV is an enveloped RNA virus that belongs to Pneumovirus genus at the Paramyxoviridae family $(10,21)$. Ribavirin is the only antiviral drug available for therapeutic use in patients infected with HRSV, but the clinical use of this medicine is restricted to children considered at risk (10). The antiviral activity of some plant extracts and its single components have already been examined against HRSV and the results varied $(19,30,40)$.

The human rotavirus (RV) is one of the most common causes of gastroenteritis around the world and its resultant diarrhoea may cause morbidity and mortality (11). The RV is a non-enveloped virus with a double strand RNA segmented genome that allows segment changes among viruses, generating diversity (11). Two vaccines against rotavirus are available since 2006, and vaccination has been routinely performed in some countries, including Brazil (25). The number of cases of gastroenteritis by rotavirus has decreased since the introduction of the vaccine, however researchers alert for the possible emergence of virus subtypes (25). The replacement of fluids and electrolytes is the only treatment successfully used for dehydration and diarrhoea; but specific treatment for rotavirus infection does not exist $(25,38)$. Extracts of plants (38) and marine sponges (12) have demonstrated antiviral activity in vitro against human and animal rotavirus.

The bovine viral diarrhoea virus (BVDV) is a significant agent of disease in cattle, causing respiratory and reproductive problems (34). BVDV is an enveloped RNA virus belonging to the Flaviviridae family (34) that has often been used as a surrogate model for the hepatitis $\mathrm{C}$ virus (HCV) since the two viruses have similar virion structure and genome organisation $(5,6)$. Like HCV, BVDV utilizes an internal ribosomal entry site (IRES) within the 5' nontranslated region (NTR) for translation of the viral polyprotein and express similar nonstructural proteins including the NS3 helicase/NTPase, and NS5B RNA-dependent RNA polymerase (6). Using BVDV as a model, it was demonstrated that natural products like hop (5) as well synthetic products like mizoribine (41), had potential antiviral activity on HCV.

Bovine herpesviruses types 1 and 5 (BoHV-1 and 5) are responsible for serious respiratory, reproductive, and neurologic diseases in cattle, while BoHV-2 is the etiologic agent of an udder infection known as herpetic mammilitis (15, 32). BoHV-1, 2 and 5 are enveloped DNA viruses classified at the Herpesviridae family. BoHV-1 and 5 belongs to the Varicellovirus genus while BoHV-2 belongs to the genus Simplexvirus (32). Antivirals are not available to the treatment of the bovine herpesviruses, although synthetic compounds currently used against human herpesviruses have been recently tested (15). BoHV-1 has also been used to test the antiviral potential of some natural products (7).

A consensus protocol for antiviral susceptibility testing is not available $(26,37)$. Several different techniques based on cythopathic effect or cell viability are applied to investigate antiviral activity $(2,12,26,37)$. The colorimetric assay MTT, based on the reduction of the tetrazolium dye (26), measures cell viability and it has been employed to access antiviral activity against different viruses $(8,16,26,40)$. Studies 
comparing plaque reduction assays and the MTT did not find significant difference in the results for both adenovirus (8) and HHV-1 (16).

Mexican oregano oil was already examined by our group for its antimicrobial properties against some bacteria and fungi (33). According to high performance liquid chromatography (HPLC) analysis, carvacrol, O-cimeno, and timol were the main components of the Lippia graveolens essential oil used in the present study and represented $56.8 \%, 32.2 \%$, and $2.7 \%$, respectively, of the total (33). Even though a large number of natural products have demonstrated antiviral activity against some of the viruses tested in our study, not any of them has yet been in clinical use. This article reports the antiviral activity of the essential oil of Lippia graveolens and its main compound, carvacrol, against human and animal viruses. In the current study, human and bovine herpesviruses represent the DNA viruses, HRSV and BVDV represent the enveloped RNA viruses, and human RV represents the non-enveloped RNA viruses.

\section{MATERIAL AND METHODS}

Essential oil and carvacrol: The essential oil of Mexican oregano (Lippia graveolens) was supplied by Essential7.com (Roswell, New Mexico, USA). To confirm its pharmaceutical composition and quality, the oil was previously analysed by chromatography (33). Carvacrol was purchased from Acros Organics (New Jersey, USA). The essential oil and carvacrol were initially diluted in methanol to a concentration of $640 \mathrm{mg} / \mathrm{ml}$ (solution I). Solution I was then diluted 1:100 in minimum essential medium (MEM) to a final concentration of $6400 \mu \mathrm{g} / \mathrm{ml}$ (solution II). Solution II was then used as the working dilution for testing.

Cells and virus: Mardin-Darby bovine kidney (MDBK) cells, MA104 cells, and HEp-2 cells were grown in MEM (GIBCO Invitrogen Corporation, Grand Island, NY, USA) containing penicillin $(100 \mathrm{U} / \mathrm{ml})$, streptomycin $(100 \mu \mathrm{g} / \mathrm{ml})$, and fungizon $(2.5 \mu \mathrm{g} / \mathrm{ml})$; and supplemented with $10 \%$ horse serum. The viral strains BVDV cytopathic Singer genotype 1, BoHV-1 Cooper, BoHV-5 607, and BoHV-2 were obtained from the laboratory of virology of the Universidade Federal de Santa Maria, Rio Grande do Sul, Brazil. The strains, HHV-1 KOS and ACVR-HHV-1 were provided by Dr. Paulo Roehe from the Universidade Federal do Rio Grande do Sul, Rio Grande do Sul, Brazil, HRSV LONG by Dr. Eurico Arruda Neto from the Universidade de São Paulo, São Paulo, Brazil, and RV DS1 by Dr. José Paulo Leite from the Fundação Oswaldo Cruz, Rio de Janeiro, Brazil. Viral stocks were prepared as follows: BVDV and BoHV-1, 2 and 5 in MDBK, HHV-1 KOS, ACVR-HHV-1 and HRSV in HEp-2, and HRV DS1 in MA104 cells and stored at $-70^{\circ} \mathrm{C}$.

Cell viability assay: The cytotoxicity of the essential oil and carvacrol was evaluated by the 3-4,5-dimethythiazol-2yl)2,5-diphenyl tetrazolium bromide (MTT) assay (M2128, Sigma), performed according to (12) and (29), with modifications. MDBK (1.6 x 10 $), \operatorname{HEp}-2$ (2 x 10 $)$, and MA104 cells were seeded onto 96-well plates and cultured in MEM and $10 \%$ horse serum for $24 \mathrm{~h}$ (MDBK and HEp-2) or $48 \mathrm{~h}(\mathrm{MA} 104)$ at $37^{\circ} \mathrm{C}$ and $5 \% \mathrm{CO}_{2}$. The medium was then removed and a serial dilution of the essential oil or carvacrol $(3200,1600,800,400,200,100,50$, and $25 \mu \mathrm{g} / \mathrm{ml})$ was added, starting by adding $200 \mu \mathrm{l}$ of solution II to the first well of each column. Cells without the essential oil were used as a control. The concentration of the essential oil or carvacrol that decreased the viability of $50 \%$ of the cells was defined as the $50 \%$ cytotoxic concentration $\left(\mathrm{CC}_{50}\right)$. After incubation for $72 \mathrm{~h}$ (MDBK), $72 \mathrm{~h}$ (HEp-2) or $72 \mathrm{~h}$ (MA104) at $37^{\circ} \mathrm{C}$ and $5 \% \mathrm{CO}_{2}$, the essential oil or carvacrol was removed, and $50 \mu \mathrm{l}$ of MTT at $1 \mathrm{mg} / \mathrm{ml}$ was added for $2 \mathrm{~h}$ to the MDBK cells and for $4 \mathrm{~h}$ to the other cells. The cells were then washed with $100 \mu \mathrm{l}$ of phosphate buffered saline (PBS) for $15 \mathrm{~min}$. Finally, the optical density of the samples was measured using an ELISA Spectra Count reader at a wavelength of $550 \mathrm{~nm}$. All results were calculated from the mean of three independent experiments 
performed in duplicate. The $\mathrm{CC}_{50}$ values were estimated from concentration-effect curves after linear regression as described in (12).

Antiviral activity: The antiviral activity of the essential oil and carvacrol was measured using the MTT assay as already described $(12,39)$, with modifications. The antiviral assays were performed at $24 \mathrm{~h}$ (MDBK and HEp-2 cells) or 48 h (MA104) after seeding, using confluent cell monolayers cultured in 96-well plates with MEM and 10\% horse serum. The essential oil or carvacrol were included in different time points as it follows:

Treatment I - The essential oil was in contact with the cell before and, also, after virus inoculation. Cells were incubated with the essential oil diluted as described in the cell viability assay, for a period of $1 \mathrm{~h}$ before virus inoculation. The oil was then removed and, each well was inoculated with $100 \mathrm{TCID} 50 / \mathrm{ml}$ doses of virus. Virus and cells were maintained in contact for $2 \mathrm{~h}$ at $37^{\circ} \mathrm{C}$, in order to allow the virus adsorption to occur. The inoculum was then replaced by fresh medium containing the essential oil.

Treatment II - The essential oil or carvacrol was added only after the removal of the virus. The virus inoculation protocol was the same as for treatment I.

Treatment III - Carvacrol was added to the cells and incubated for $1 \mathrm{~h}$ before virus inoculation. The virus inoculation procedure was performed as described for treatment I. After the virus removal the inoculum was replaced by fresh medium without carvacrol.

For all the treatments, the MTT procedure was performed $72 \mathrm{~h}$ later according protocol described in cell viability assay. The concentration that reduced the absorbance of infected cells to $50 \%$ when compared to cell and virus controls was considered the effective concentration $\left(\mathrm{EC}_{50}\right)$. The $\mathrm{EC}_{50}$ was calculated according the following equation: $[(\mathrm{A}-\mathrm{B}) /(\mathrm{C}-\mathrm{B})$ $\mathrm{x}$ 100], where A is the control sample absorbance, $\mathrm{B}$ is the cell control absorbance, and $\mathrm{C}$ is the virus control absorbance. The selectivity index (SI) was calculated using the $\mathrm{CC}_{50}$ and $\mathrm{EC}_{50}$ data and applying the formula $\mathrm{SI}=\mathrm{CC}_{50} / \mathrm{EC}_{50}$.

\section{RESULTS AND DISCUSSION}

Mexican oregano was effective in inhibiting five of the eight viruses examined. The results of the antiviral activity of the essential oil against five DNA viruses (HHV-1, ACVRHHV-1, BoHV-1, BoHV-2, BoHV-5) and three RNA viruses (HRSV, RV, BVDV) are summarised at Table 1, while Table 2 displays the results of carvacrol activity against the same viruses, excluding BoHV-1 and 5. Acyclovir was the positive control for HHV-1, while ribavirin was the positive control for HRSV, RV, and BVDV. Two different treatment protocols were followed to investigate the effects of Mexican oregano oil on viruses. For treatment I, oil addition was performed before and after viral inoculation, while for treatment II, the oil was added only after viral inoculation. The best results were observed following the first protocol for three of the five viruses (Table 1).

In general, the essential oils from different plants examined in vitro have shown low toxicity to the cell cultures tested $(2,14,27)$. In this study, the toxicity of Mexican oregano essential oil varied according to cell type, with the lowest toxicity to HEP2 cells (Table 1). Based on the $\mathrm{CC}_{50}$, the best SIs were observed for the human viruses ACVR-HHV-1 and HRSV (Table 1).

Time-on-addition experiments using the essential oils of anise, hyssop, thyme, ginger, chamomile, sandalwood (27), and Santolina insularis (14) have shown that the activity of the essential oils is most pronounced when viruses or cells were treated before inoculation. These oils were tested against HHV1 and 2, which are enveloped viruses. It has been suggested that the oils may interact with the viral envelope and glycoproteins of HHV (27).

All of the five viruses inhibited by Mexican oregano oil were enveloped. The oil evidenced antiviral activity against these viruses when the cells were pre- and post-treated, 
whereas only two of these viruses were also effectively inhibited when the oil was added only after viral inoculation (Table 1). Although there were only two different protocols performed for oil addition in this study, the presence of the oil before viral inoculation seemed to make a difference. It should be noted that for BVDV, however, the oil was more efficient when applied only after inoculation with the virus (Table 1).

Table 1. Antiviral activity of the essential oil of Mexican oregano (Lippia graveolens) against human and animal viruses

\begin{tabular}{llllll}
\hline & & Treatment $\mathbf{I}^{\mathbf{a}}$ & \multicolumn{2}{c}{ (pre/post) } & \multicolumn{2}{c}{ Treatment II $^{\mathbf{b}}$ (post) } \\
Virus & $\mathbf{C C}_{\mathbf{5 0}}$ & $\mathbf{E C}_{\mathbf{5 0}}$ & $\mathbf{S I}_{\mathbf{5 0}}$ & $\mathbf{E C}_{\mathbf{5 0}}$ & $\mathbf{S I}_{\mathbf{5 0}}$ \\
\hline HHV-1 & 735 & 99.6 & 7.4 & na & na \\
ACVR-HHV-1 & 735 & 55.9 & 13.1 & 321.6 & 2.3 \\
BoHV-1 & 568 & na & na & na & na \\
BoHV-2 & 568 & 64 & 8.8 & 58.4 & 9.7 \\
BoHV-5 & 568 & na & na & na & na \\
HRSV & 735 & 68 & 10.8 & na & na \\
RV & 391.5 & na & na & na & na \\
BVDV & 568 & 123 & 4.6 & 78 & 7.2 \\
\hline
\end{tabular}

${ }^{\mathrm{a}}$ Essential oil present before and after viral inoculation; ${ }^{\mathrm{b}}$ essential oil present only after viral inoculation; $\mathrm{CC}_{50}=50 \%$ cytotoxic concentration $(\mu \mathrm{g} / \mathrm{ml}) ; \mathrm{EC}_{50}=50 \%$ effective concentration $(\mu \mathrm{g} / \mathrm{ml}) ; \mathrm{SI}_{50}=$ selectivity index $\left(\mathrm{CC}_{50} / \mathrm{IC}_{50}\right) ; \mathrm{HHV}-1=$ human herpes virus 1; ACVR-HHV-1 = acyclovir-resistant human herpes virus 1 ; BoHV-1= bovine herpesvirus 1 ; na = no activity; BoHV-2 = bovine herpesvirus 2; BoHV-5= bovine herpesvirus 5; HRSV= human respiratory syncytial virus; RV= human rotavirus; BVDV= bovine viral diarrhoea virus.

Meanwhile, the oil had no antiviral effects on two of the three bovine herpesviruses examined, inhibiting BoHV-2 but not BoHV-1 and 5, which are also enveloped viruses. Since these are all bovine pathogens, differences among the viral envelopes probably does not explain the selective antiviral activity. There are genomic differences among these viruses, as BoHV-2 is classified in the Simplexvirus genus while BoHV-1 and 5 are classified as the Varicellovirus genus (32). It would be interesting to test other viruses in the same genus as BoHV1 and 5 to check for a group difference.

Carvacrol was found to have antiviral effects on five of the viruses tested, but unlike the essential oil, it was effective against human RV but not against BoHV-2 (Table 2). Carvacrol was also not as effective as the essential oil against HHV, BVDV, and HRSV (Table 2). Still another difference is that the major component alone showed higher cell toxicity than the essential oil.

Carvacrol has been identified as the main component of several essential oils with antimicrobial activity (28, 36). However, this compound and antimicrobial activity are not always clearly correlated. For instance, the essential oil of Origanum acutidens has demonstrated no antiviral activity against HHV-1 even though carvacrol composed $72 \%$ of the oil (36). Conversely, methanol extracts from the same plant inhibited HHV-1 and such activity has been attributed to phenolic acids (36).

The difference between the antiviral activity of the essential oil and carvacrol alone may be due to the synergistic effect of the components of the oil. A similar effect has already been described for Staphylococcus aureus and Pseudomonas aeruginosa (28). Both were inhibited in vitro by the oregano essential oil and by the components carvacrol and thymol, but the oil inhibition was mainly attributed to the additive antimicrobial action of these two compounds (28).

Mexican oregano essential oil and its main component, carvacrol, were effective against RNA and DNA viruses (Tables 1 and 2). This dual efficacy has advantages over common antiviral drugs, which generally act on only RNA or DNA viruses or may even be specific to a single virus or group of viruses (13). To identify other versatile antivirals, several 
plant products have been screened against groups of RNA and DNA viruses with variable results $(19,35)$. Significant in vitro antiviral activity against three RNA viruses was observed for extracts derived from the roots of Eleutherococcus senticosus but no activity was detected against two DNA viruses in the same experiment (19). Another study found only one plant extract of fifteen tested that was able to inhibit two RNA and DNA viruses (35). Although further studies are needed to determine the mechanisms of action and viral activity of Mexican oregano oil and carvacrol, a broad spectrum of action is very desirable for any antiviral candidate.

Apparently the essential oil and its purified component are able to inhibit the viruses in different stages of virus infection and replication since the essential oil was able to inhibit viruses before but also after virus inoculation while carvacrol was effective only when added after virus inoculation (Tables 1 and 2). Very interesting is the fact that the carvacrol activity was present after virus inoculation for viruses with either RNA or DNA genome. As RNA and DNA replication strategies require different steps and the action of diverse classes of enzymes and other regulatory factors (3), it could suggest that the major component way of action is not on genome replication but on other step of virus replication common to all viruses. More detailed time-on-addition experiments are being performed to elucidate this issue.

It is important to emphasize the antiviral activity of Mexican oregano and carvacrol against HHV-1 sensitive as well as HHV-1 resistant to acyclovir (Tables 1 and 2). Since any compound showing a $\mathrm{SI}=4$ was considered a potential antiviral candidate to herpesviruses (1), the mexican oregano and its major component carvacrol fulfill the requirements for both HHV-1 sensitive as well resistant to acyclovir (Table1 and 2). Besides, BoHV-2, another herpesvirus classified at the genus Simplexvirus, was also effectively inhibited by Mexican oregano essential oil (Table 1). A great number of natural products were evaluated for its anti-herpetic activity $(24,26)$, but none of the compounds examined is available for use yet. Even though the antiviral activity of the oil and its major component was observed in different time points of viral replication, both the oil and its major were more effective against ACVR-HHV-1 than HHV-1 sensitive to acyclovir. Acyclovir is a nucleoside analogue acting on the viral genome replication which functions as DNA chain terminator preventing elongation of viral DNA (13). Mutations on the timidine kinase gene of the $\mathrm{HHV}-1$, makes it resistant to acyclovir (18). The fact that Mexican oregano oil and carvacrol demonstrated activity on ACVR-HHV-1 may indicate that the mechanism of action is different from acyclovir.

Table 2. Antiviral activity of carvacrol against human and animal viruses

\begin{tabular}{llllll}
\hline & & Treatment III & \multicolumn{2}{c}{ (pre) } & \multicolumn{2}{c}{ Treatment II $^{\mathbf{b}}$ (post) } \\
Virus & $\mathbf{C C}_{\mathbf{5 0}}$ & $\mathbf{E C}_{\mathbf{5 0}}$ & $\mathbf{S I}_{\mathbf{5 0}}$ & $\mathbf{E C}_{\mathbf{5 0}}$ & $\mathbf{S I}_{\mathbf{5 0}}$ \\
\hline HHV-1 & 250 & na & na & 48.6 & 5.1 \\
ACVR-HHV-1 & 250 & 984.5 & 0.2 & 28.6 & 8.7 \\
BoHV-2 & 215 & 1829.9 & 0.1 & 663 & 0.3 \\
HRSV & 250 & 12889 & 0.01 & 62 & 4.15 \\
RV & 920 & 530 & 1.7 & 27.9 & 33 \\
BVDV & 215 & 117 & 1.8 & 50.7 & 4.2 \\
\hline a & 215 &
\end{tabular}

${ }^{\mathrm{a}}$ Carvacrol present only before viral inoculation; ${ }^{\mathrm{b}}$ carvacrol present only after viral inoculation; $\mathrm{CC}_{50}=\mathrm{CC}_{50}=50 \%$ cytotoxic concentration $(\mu \mathrm{g} / \mathrm{ml}) ; \mathrm{EC}_{50}=50 \%$ effective concentration $(\mu \mathrm{g} / \mathrm{ml}) ; \mathrm{SI}_{50}=$ selectivity index $\left(\mathrm{CC}_{50} / \mathrm{IC}_{50}\right) ; \mathrm{HHV}-1=$ herpes simplex virus 1; na = no activity; ACVR-HHV-1 = acyclovir-resistant herpes simplex virus 1 ; BoHV-2 = bovine herpesvirus 2 ; HRSV = respiratory syncytial virus; $\mathrm{RV}=$ human rotavirus; $\mathrm{BVDV}=$ bovine viral diarrhoea virus.

The SI value demonstrated for the essential oil against HRSV is also worth of note, even though there are literature descriptions of very high values of SI for a compound isolated from $L$ deflexicalyx $(\mathrm{SI}=5880)(30)$ and also for a constituent of 
Agastache rugosa (SI=898.2) (40). A safe vaccine against the virus is not yet commercially available (21), so an antiviral that is active against HRSV without toxicity may be a good alternative. Ribavirin has already been used to treat some HRSV-induced diseases, although it is only recommended for special cases involving high-risk children due to its toxicity (10). Since Mexican oregano oil had significant antiviral effects on HRSV and low cytotoxicity, it would be interesting to compare the effects of the oil and its derivative alone or in combination with ribavirin.

Mexican oregano essential oil was not able to inhibit rotavirus in any of the time points examined (Table 1), while carvacrol was effective when added after virus inoculation (Table 2). Such results were not expected given that carvacrol is a major component of the essential oil. However, the essential oil is a complex of different amounts and quality of compounds (2). Such complexity generates diversity in the pharmacological activities of the essential oils and their components. In some cases, the essential oil demonstrates the best biological activity (20), and in other cases the major components of the oils demonstrates similar pharmacological activity (9), or, even better activity than the essential oil (2).

On the other hand, the most obvious difference between $\mathrm{RV}$ and the other viruses tested is the absence of the envelope. As already discussed before, there are evidences that the essential oils of a significant number of plants have some action on the viral envelope or cell structure $(14,27)$. Since the enveloped viruses fusion its envelope with the cell or endocytic vesicle membrane before entry (22); it is possible that the essential oils interfere with such fusion which would have no effect on RV. Some compounds examined against human as well animal rotavirus showed action before entrance of the virus or immediately after; but the compounds were not oil (12, 38). The hot water extract of Stevia rebaudiana inhibited virus binding to cell (38), and the acqueous and methanolic extracts of some genus of marine sponges collected off Brazilian Coast showed the best inhibition of RV-SA11 when the compounds were included simultaneously with the virus (12).

In the present study, only carvacrol had effect on rotavirus, and it was after virus inoculation. Then, the mechanism of action for carvacrol probably is different from those already described $(12,38)$. Nevertheless, independently of the mechanisms of action, the activity of carvacrol on rotavirus is very promising. Further, diarrhea is a complex disease that may have viral, bacterial or even parasitic causes (4). Thus, alternative treatments using compounds with wide antimicrobial activity against diverse agents of diarrhea is advantageous. Regarding to that, carvacrol also exhibited antimicrobial activity against other diarrhea agents such as Salmonella enterica and Escherichia coli O157:H7 (17).

Finally, the efficacy of Mexican oregano on BVDV is lower if compared to its activity on the other viruses examined in this issue (Table 1). However, the antiviral activity of the oil when added after virus inoculation is comparable to the results obtained $(\mathrm{SI}=6)$ by another group studying the activity of the hop constituents against BVDV (5). The results may not have relevance for the bovine which are the host of the virus due to the unlikely applicability of antiviral to that species. Nonetheless, considering that a compound that inhibits BVDV replication has a potential antiviral activity against $\mathrm{HCV}(6)$, more detailed studies with BVDV could be suggested.

In conclusion, the activity of Mexican oregano oil against ACVR-HHV-1 and HRSV as well as that of carvacrol against $\mathrm{RV}$ warrant further studies to explore the mechanisms of action of the compounds.

\section{ACKNOWLEDGEMENTS}

This research was supported by Grant \# 473564/2006-8 from CNPq. Both Dr. Rudi Weiblen and Dr. Sydney Hartz Alves are recipients of CNPq fellowships.

\section{REFERENCES}

1. Amoros, M., Simoes, C.M.O., Girre, L., Sauvager, F., Cormier, M. 
(1992). Synergistic effect of flavones and flavonols against herpes simplex virus type 1 in cell culture. Comparison with the antiviral activity of propolis. J. Nat. Prod., 55 (12), 1732-1740.

2. Astani, A., Reichling, J., Schnitzler, P. (2010). Comparative study on the antiviral activity of selected monoterpenes derived from essential oils. Phytother. Res., 24 (5), 673-679.

3. Ball, L.A. (2007).Virus replication strategies. In: Knipe, D.M., Howley, P.M. (eds). Fields Virology. Lippincott Williams \& Wilkins, Philadelphia, USA, p.119-139.

4. Bernstein, D.I. (2009). The changing epidemiology of rotavirus gastroenteritis. Introduction. Pediatr. Infect. Dis. J., 28 (3 Suppl), S49.

5. Buckwold, V.E., Wilson, R.J.H., Nalca, A., Beer, B.B., Voss, T.G., Turpin, J.A., Buckheit III, R.W., Wei, J., Wenzel-Mathers, M., Walton, E.M., Smith, R.J., Pallansch, M., Ward, P., Wells, J., Chuvala, L., Sloane, S., Paulman, R., Russell, J., Hartman, T., Ptak, R. (2004). Antiviral activity of hop constituents against a series of DNA and RNA viruses. Antivir. Res., 61 (1), 57-62.

6. Buckwold, V. E., Beer, B. E., Donis, R. O. (2003). Bovine viral diarrhoea virus as a surrogate model of hepatitis $\mathrm{C}$ virus for the evaluation of antiviral agents. Antivira.l Res., 60 (1), 1-15.

7. Bruggemann, R., Orlandi, J.M., Benati, F.J., Faccin, L.C., Mantovani, M.S., Nozawa, C., Linhares, R.E.C. (2006). Antiviral activity of Agaricus blazei Murrill ss. Heinem extract against human and bovine herpesviruses in cell culture. Braz. J. Microbiol., 37 (4), 561-565.

8. Chen, C.H., Chou, T.W., Cheng, L.H., Ho, C.W. (2011) In vitro antiadenoviral activity of five Allium plants. J. Taiw. Inst. Chem. Eng., 42 (2), 228-232.

9. Chiang, L. C., Nig, L. T., Cheng, P. W., Chiang, W., Lin, C. C. (2005). Antiviral activities of extracts and selected pure constituents of Ocimum basilicum. Clin. Exp. Pharmacol. Physiol., 32 (10), 811-816.

10. Chidgey, S. M., Broadley, K. J. (2005). Respiratory syncytial virus infections: characteristics \& treatment. J. Pharm. Pharmacol., 57 (11), 1371-1381.

11. Clark, B., Mckendrick, M. A. (2004). Review of viral gastroenteritis. Curr. Opin. Infect. Dis., 17 (5), 461-469.

12. Da Silva, A.C., Kratz, J.M., Farias, F.M., Henriques, A.T., Dos Santos, J., Leonel, R.M., Lerner, C., Mothes, B., Barardi, C.R.M., Simões, C.M.O. (2006). In vitro antiviral activity of marine sponges collected off Brazilian coast. Biol. Pharm. Bull. 29 (1), 135-140.

13. De Clercq, E. (2004). Antiviral drugs in current clinical use. J. Clin. Virol., 30(2), 115-133.

14. De Logu, A., Loy, G., Pellerano, M. L., Bonsignore, L., Schivo, M. L. (2000). Inactivation of HSV-1 and HSV-2 and prevention of cell-to-cell virus spread by Santolina insularis essential oil. Antivir. Res., 48 (3), 177-185.

15. Dezengrini, R., da Silva, S.C., Weiss, M., Kreutz, L.C., Weiblen, R.,
Flores, E.F. (2010). Activity of three antiviral drugs against bovine herpesviruses 1, 2 and 5 in cell culture. Pesq. Vet. Bras., 30 (10), 855860.

16. Freitas, A.M., Almeida, M.T.R., Andrighetti-Fröhner, C.R., Cardozo, F.T.G.S., Barardi, C.R.M., Farias, M.R., Simões, C.M.O. (2009). Antiviral activity-guided fractionation from Araucaria angustifolia leaves extract. J. Ethnopharmacol., 126 (3), 512-517.

17. Friedman, M., Zhu, L., Yelena, F., Sadhana, R. (2009). Carvacrol facilitates heat-induced inactivation of escherichia coli O157: $\mathrm{H} 7$ and inhibits formation of heterocyclic amines in grilled ground beef patties. J. Agr. Food Chem., 57 (5), 1848-1853.

18. Gilbert, C., Bestman-Smith, J., Boivin, G. (2002). Resistance of herpesviruses to antiviral drugs: Clinical impacts and molecular mechanisms. Drug Resist. Update, 5 (2), 88-114.

19. Glatthaar-Saalmuller, B., Sacher, F., Esperester, A. (2001). Antiviral activity of an extract derived from roots of Eleutherococcus senticosus. Antivir. Res., 50 (3), 223-228.

20. Goñi, P., López, P., Sánchez, C., Gómez-Lus, R., Becerril, R., Nerín, C. (2009). Antimicrobial activity in the vapour phase of a combination of cinnamon and clove essential oils. Food Chem., 116 (4), 982-989.

21. Hashem, M., Hall, C. B. (2003). Respiratory syncytial virus in healthy adults: the cost of a cold. J. Clin. Virol., 27 (1), 14-21.

22. Helenius, A. (2007). Virus entry and uncoating. In: Knipe, D.M., Howley, P.M. (eds). Fields Virology. Lippincott Williams \& Wilkins, Philadelphia, USA, p.99-118.

23. Hernández, T., Canales, M., Avila, J. G., Duran, A., Caballero, J., Vivar, A. R. d., Lira, R. (2003). Ethnobotany and antibacterial activity of some plants used in traditional medicine of Zapotitlán de las Salinas, Puebla (México). J. Ethnopharmacol., 88 (2-3), 181-188.

24. Jassim, S. A., Naji, M. A. (2003). Novel antiviral agents: a medicinal plant perspective. J Appl. Microbiol., 95 (3), 412-427.

25. Khan, M.A., Bass, D.M. (2010). Viral infections: New and emerging. Curr. Opin. Gastroen., 26 (1), 26-30.

26. Khan, M.T.H., Ather, A., Thompson, K.D., Gambari, R. (2005). Extracts and molecules from medicinal plants against herpes simplex viruses. Antivir. Res., 67 (2), 107-119.

27. Koch, C., Reichling, J., Schneele, J., Schnitzler, P. (2008). Inhibitory effect of essential oils against herpes simplex virus type 2 . Phytomedicine, 15 (1-2), 71-78.

28. Lambert, R. J., Skandamis, P. N., Coote, P. J., Nychas, G. J. (2001). A study of the minimum inhibitory concentration and mode of action of oregano essential oil, thymol and carvacrol. J. Appl. Microbiol., 91 (3), 463-462.

29. Mosmann, T. (1983). Rapid colorimetric assay for cellular growth and survival: Application to proliferation and cytotoxicity assays. $J$. Immunol. Met., 65 (1-2), 55-63. 
30. Ojwang, J.O., Wang, Y.-H., Wyde, P.R., Fischer, N.H., Schuehly, W., Appleman, J.R., Hinds, S., Shimasaki, C.D. (2005). A novel inhibitor of respiratory syncytial virus isolated from ethnobotanicals. Antiviral Res. 68 (3), 163-172.

31. Pascual, M. E., Slowing, K., Carretero, E., Sanchez Mata, D., Villar, A. (2001). Lippia: traditional uses, chemistry and pharmacology: a review. J. Ethnopharmacol., 76(3), 201-214.

32. Pellet, P. E., Roizman, B. (2007). The family Herpesviridae: a brief introduction. In: Knipe, D. M., Howley, P. M. (eds.). Fields virology. Lippincott Williams \& Wilkins, Philadelphia, USA, p.2479-2499.

33. Pozzatti, P., Scheid, L. A., Spader, T. B., Atayde, M. L., Santurio, J. M., Alves, S. H. (2008). In vitro activity of essential oils extracted from plants used as spices against fluconazole-resistant and fluconazolesusceptible Candida spp. Can. J. Microbiol., 54 (11), 950-956.

34. Ridpath, J.F. (2010). Bovine Viral Diarrhea Virus: Global Status. Vet. Clin. N. AM-Food A., 26 (1), 105-121.

35. Ruffa, M. J., Wagner, M. L., Suriano, M., Vicente, C., Nadinic, J., Pampuro, S., Salomon, H., Campos, R. H., Cavallaro, L. (2004). Inhibitory effect of medicinal herbs against RNA and DNA viruses. Antivir. Chem. Chemother., 15 (3), 153-159.

36. Sökmen, M., Serkedjieva, J., Daferera, D., Gulluce, M., Polissiou, M.,
Tepe, B., Akpulat, H. A., Sahin, F., Sokmen, A. (2004). In vitro antioxidant, antimicrobial, and antiviral activities of the essential oil and various extracts from herbal parts and callus cultures of Origanum acutidens. J. Agric. Food Chem., 52 (11), 3309-3312.

37. Swierkosz, E.M., Hodinka, R.L. (1999). Antiviral agents and susceptibility tests. In: Murray, P.R., Baron, E.J., Pfaller, M.A., Tenover, F.C., Yolken, R.H. (eds). Manual of Clinical Microbiology. American Society for Microbiology, Washington, DC, p.1624-1639.

38. Takahashi, K., Matsuda, M., Ohashi, K., Taniguchi, K., Nakagomi, O., Abe, Y., Mori, S., Sato, N., Okutani, K, Shigeta, S. (2001). Analysis of anti-rotavirus activity of extract from Stevia rebaudiana. Antivir. Res., 49 (1), $15-24$

39. Takeuchi, H., Baba, M., Shigeta, S. (1991). An application of tetrazolium (MTT) colorimetric assay for the screening of anti-herpes simplex virus compounds. J. Virol. Met., 33 (1-2), 61-71.

40. Wang, K.C., Chang, J.S., Chiang, L.C., Lin, C.C. (2009). 4Methoxycinnamaldehyde inhibited human respiratory syncytial virus in a human larynx carcinoma cell line. Phytomedicine, 16 (9), 882-886.

41. Yanagida, K., Baba, C., Baba, M. (2004). Inhibition of bovine viral diarrhea virus (BVDV) by mizoribine: Synergistic effect of combination with interferon- $\alpha$. Antivir. Res., 64 (3), 195-201. 